Tsaqofiya : Jurnal Pendidikan Bahasa dan Sastra Arab

Vol. 4 No. 1 Januari 2022, 75-93

P-ISSN : 2685-7022, E-ISSN : 2685-7103

DOI: $10.21154 /$ tsaqofiya.v4i1.81

\title{
Semiotika Michael Riffaterre Dalam Puisi Fî ‘Ainika Unwanî Karya Faruq Juwaidah
}

\author{
Fatimatuz Zahro' \\ UIN Sunan Kalijaga, Yogyakarta \\ zahrokholik1234@gmail.com
}

\section{Abstract}

This study aims to analyze the structure and meaning of the poetry text fii ainika unwanii using Riffatere's semiotic theory. Methods of This research uses a qualitative method and Riffaterre's semiotic approach. This study describes the reading of heuristics, hermeneutics and described by matrices, models, variants and hypograms in fii ainika unwani poetry. This type of research uses qualitative, data in the form of stanzas or lines in the poem fii ainika unwani by Faruq Juwaidah. The data source is a poetry text consisting of 2 stanzas and 32 lines. While the presentation of the data is done by drawing conclusions by describing the results of the application of Riffatere's semiotic theory in the form of words, sentences and paragraphs in a systematic, factual and accurate manner, semantic validity is done by reading and repeating poetry and the results that are relevant to the theory. The results show that the heuristic reading in the form of translation of the meaning is generally described about love. love, love, fear of loss and hope. The variant of the poem that is emphasized is in the first stanza which includes the essence, namely: he said, you will forget me. And the variant in the thirteenth stanza that answers questions and hopes in the first stanza is "I answer, love is my faith". The model in this poem in general is that when we love the right person it will make us better to love the wrong person, it is love that will kill the lovers. The hypogram in this poem is motivated by feelings expressed through hope.

Keywords: Faruq Juwaidah, poetry, romantic, Riffaterre's semiotics

\section{Abstrak}

Penelitian ini bertujuan untuk menganalisis struktur dan makna teks puisi fii ainika unwanii menggunakan teori semiotika Riffatere. Metode penelitian ini menggunakan metode kualitatif dan pendekatan semiotik Riffaterre. Penelitian ini mendeskripsikan pembacaan heuristic, hermeneutic dan dideskripsikan dengan matriks, model, varian dan hipogram dalam puisi fii ainika unwani. Jenis Penelitian menggunakan kualitatif, data berupa bait atau baris dalam puisi fii ainika unwani karya Faruq Juwaidah. Sumber data berupa teks puisi yang terdiri dari 2 bait dan 32 baris. Penyajian data dilakukan dengan penarikan kesimpulan dengan mendeskripsikan hasil dari penerapan teori semiotik Riffatere berupa kata, kalimat dan paragraf secara sistematis, faktual dan akurat, validitas semantik dilakukan dengan membaca dan meneliti secara berulang-ulang terhadap puisi dan hasil 
yang relevan dengan teori. Hasil dari pembacaan heuristik berupa terjemahaan arti dari puisi Arab karya Faruq Juwaidah secara umum menggambarkan tentang kasih sayang, cinta, takut kehilangan serta harapan. Varian puisi yang ditekankan yaitu pada bait pertama yang telah mecakup inti, yaitu: dia berkata, kau akan melupakanku. Dan varian pada bait ke tiga belas yang menjawab ketakutan dan harapan pada bait pertama yaitu "aku menjawab, mencintaimu adalah imanku". Model dalam puisi ini secara umum adalah ketika kita mencintai orang yang tepat akan membuat kita lebih baik sedangkan mencintai orang yang salah, cintalah yang akan membunuh para pecinta. Hipogram pada puisi ini dilatarbelakangi oleh pengungkapan perasaan yang diceritakan melalui harapan.

Kata kunci: Faruq Juwaidah, puisi, romantic, semiotika Riffaterre

\section{PENDAHULUAN}

Puisi merupakan ungkapan hati penyair yang dituangkan dalam karya sastra yang indah dan padat makna. Bentuk perasaan tersebut ditujukan untuk menggambarkan ekspresi diri, imajinasi, kritik, pengalaman dll. Pengertian puisi menurut KBBI adalah ragam sastra dengan penggunaan bahasa yang masih memperhatikan matra, irama, penyusunan lirik, bait atau irama. Sedangkan puisi menurut para ahli, yaitu:

1. Usman Awang yang mengatakan bahwa puisi bukanlah nyanyian orang yang sedang mencari ketenangan dan kepuasan dalam menulis puisinya.

2. Herman J. Waluyo, pengertian puisi menurut beliau adalah pengungkapan pikiran dan perasaan penyair disusun dalam kekuatan bahasa melalui struktur fisik dan struktur batinnya.

3. Putu Arya Tirtawirya, ungkapan secara implisit, samar, maknanya tersirat dan condong menggunakan makna konotatif.

4. Muhammad Hj. Selleh, karya sastra yang kental dengan musik bahasa yang berisi kebijaksanaan dan tradisi penyair yang menjadikan kita lebih bijaksana.

5. Herbert Spencer, bentuk pengungkapan gagasan yanga sifatnya emosional dengan mempertimbangkan keindahannya.

6. Hermen Waluyo, menurut beliau karya sastra berupa puisi merupakan karya yang paling awal ditulis oleh manusia.

7. James Reevas, puisi adalah ekspresi bahasa yang kaya dan penuh daya pikat. ${ }^{1}$

Puisi fii ainika unwanii Karya Faruq Juwaidah ini merupakan puisi Arab Modern yang sangat menginspirasi. Faruq Juwaidah dikatakan bukan seperti Nizar

${ }^{1}$ Agnes P. Amelia S., Seni Mengenal Puisi. (Bogor: Guepedia, 2020). 
yang mencintai dan selalu dicintai perempuan. Ia hanya seseorang yang mengibarkan puisi romantisnya dalam sebuah puisi. Puisi ini menceritakan tentang cinta yang begitu besar dan takut kehilangan, bentuk cinta yang membuat semangat dan hidup.

Puisi merupakan sistem tanda yang memiliki makna. Akan tetapi pemaknaan pada puisi diperlukan pemaknaan dari pembaca. Oleh karena itu, analisis ini menggunakan teori Semiotika Riffaterre agar dapat diketahui maknanya. Tahapan yang digunakan untuk analisis ini dengan pembacaan Heuristik, hermeneutik, matriks, model varian dan hipogram. Dengan tahapan tersebut, penulis berharap akan ada pemaknaan yang lebih jelas dan mendalam.

Alasan pemilihan puisi ini adalah adanya nilai seni dalam pengalaman jiwa yang tinggi diungkapkan dalam kata, pengalaman jiwa nilainya semakin tinggi apabila meliputi: ketuhan jiwa dan pengalaman jiwa, dan akan semakin tinggi bila pengalaman semakin kuat, pengalaman jiwa semakin tingi jika pengalaman semakin luas. ${ }^{2}$

Beberapa Penelitian yang Relevan, pertama adalah Penelitian yang dilakukan oleh Yulia Nasrul Latifi, 2013. Puisi ana karya Nazik Al-Mala'ikah (analisis semiotik Riffaterre), penelitian kedua adalah M. Fawaid al Fikry dkk. 2019. Mantra Petapa Alas Purwo: Kajian Semiotika Riffaterre.

\section{METODE}

Metode Penelitian ini menggunakan metode kualitatif dan pendekatan semiotik Riffaterre. Penelitian ini mendeskripsikan pembacaan heuristik, hermeneutik dan dideskripsikan dengan matriks, model, varian dan hipogram dalam puisi fii ainika unwani. Salah satu bentuk prosedur penelitian kualitatif ini melibatkan penulis dalam penelitian. ${ }^{3}$ Jenis Penelitian ini menggunakan metode kualitatif, sumber data berupa data primer dan sekunder, data primer berupa bait atau baris dalam puisi fii ainika unwani karya Faruq Juwaidah. Sumber data berupa teks puisi yang terdiri dari 2 bait dan 32 baris. Dan data sekunder berupa buku pustaka yang relevan menunjang Penelitian. Teknik pengumpulan data dengan pengamatan, pembacaan heuristik, hermeneutik. Pengamatan dengan cara membaca puisi bahasa

2 Yulia Nasrul L. Puisi ana karya Nazik Al-Mala'ikah (Analisis Semiotik Riffaterre). Yogyakarta: Adabiyyat: Jurnal Bahasa dan Sastra. Vol. XII. No 1. (2013) Hal. 27.

${ }^{3}$ Kodrat Eko, Andayani. Strategi Ampuh Memahami Makna Puisi: Teori Semiotika Michael Riffaterre dan Penerapannya, (Bandung: Eduvision, 2019). 
Arab kemudian diterjemahkan kedalam bahasa indonesia dilakukan dengan teliti dan cermat untuk mendapatkan data sesuai yang diinginkan. Analisis data dilakukan dengan memahami puisi yang memiliki ketidaklangsungan bahasa yang akan terjadi penyimpangan arti, penggantian arti dan penciptaan arti. Kemudian pembacaan heuristik yang dilakukan untuk menghasilkan arti secara keseluruhan sesuai dengan tata bahasa dan pembacaan hermeneutik yang merupakan bentuk penafsiran. Pembacaan selanjutnya untuk memperdalam Penelitian yaitu mendalami tema masalah dengan mencari matriks, model dan varian-variannya. Matriks merupakan kata kunci atau inti dari serangkaian teks yang diaktualisasikan dalam model, model adalah pengembangan teks dengan pemaparan yang diaktualisasikan dalam bentuk varian. ${ }^{4}$ Penyajian data dilakukan dengan penarikan kesimpulan dengan mendeskripsikan hasil dari penerapan teori semiotik Riffatere berupa kata, kalimat dan paragraf secara sistematis, faktual dan akurat. Selain itu, teknik pengumpulan data dilakukan validitas semantik dengan membaca dan meneliti secara berulangulang terhadap puisi dan hasil yang relevan dengan teori yang digunakan yaitu teori Rifaterre.

\section{PEMBAHASAN}

Puisi menurut Riffatere adalah sesuatu yang berbeda dengan yang lain dalam penggunaan bahasa. Puisi selalu menyatakan konsep secara tidak langsung, memiliki makna yang lain dan tersembunyi, inilah yang menjadikan perbedaan empiris pada cara teks puisi membawakan makna. ${ }^{5}$ Puisi juga memiliki ciri lain yaitu kesatuannya yang memiliki keterbatasan. Sedangkan sumber inspirasi penulis puisi adalah alam, hal itu berlaku untuk puisi romantis. Individualisme dalam puisi dianggap cerminan perasaan penulis yang di tuangkan dalam karya berupa ekspresi benci atau cinta. ${ }^{6}$ Keberadaan perasaan yang sangat kuat dari penulis, maka membuat puisi sulit didefinisikan tanpa menghitungnya. Semiotika adalah studi tentang penanda dan

\footnotetext{
${ }^{4}$ Hartono. Semiotika Riffaterre dalam Durrga Umayi karya Y. B Mangunwijaya. (Yogyakarta: Universitas Negeri Yogyakarta, 2014).

${ }^{5}$ Michael Riffatere. Semiotics Of Poetry (Bloomington; Indiana University Press, 1878). Hal. 1

${ }^{6}$ Raheleh, Barador. Anita L. Semiotika puisi Riffatere dalam membaca ulang "Bright Star" karya John Keats dan Sepehri "ke taman Rekan Wisatawan". Iran: Asian Journal of Multidiscciplinary Studies. Vol: 2, issue 9 (2014).
} 
petanda yang menemukan sebuah keterkaitan yang tujuannya untuk mengungkapkan makna. Tanda juga dipelajari pada fungsi komunikatifnya. ${ }^{7}$

Hipotesis dasar Michael Riffatere tergambar jelas dalam karyanya semiotic of Poetry yang menyatakan " the shift from meaning to significance necessitates the concept of interpretant, that is a sign that translates the texts surface signs and explains what else the text suggest. ${ }^{8}$ Yang berarti mengkaji sebuah arti pemaknaan ini dibutuhkan interpretan untuk menggali makna tanda yang kompleks dan komprehensif. ${ }^{9}$ Fungsi makna dalam karya sastralah yang menjadi harapan dan keinginan pembaca agar persepsi-persepsi di dalam pikirannya terjawab dengan bantuan makna. Oleh karena itu, Michael Riffatere menolak jika maksud sebuah puisi harus sama dengan maksud penulis, karena pembaca akan merasa tersesat dengan maksud dan tujuan penulis. akan tetapi, pembaca akan menemukan makna puisi dipengaruhi oleh mekanisme semiotika dalam teks itu sendiri.

Puisi Faruh Juwaidah merupakan sastrawan masa modern. Beliau dikenal dengan karya romantisme yang menjadi kecenderungan utama beliau. Karya beliau menggambarkan bentuk cinta yang tenang, kesederhanaan dan kedalaman bentuk cinta. Kelebihan puisi Faruq Juwaidah juga juga menyelipkan kritis dalam puisipuisinya. Akan tetapi, puisi tersebut tidak mengandung kesan yang anarki dan frontal menurut publik Arab. Faruq Juwaidah tercatat telah menyumbangkan 20 karya dalam berbagai genre, karya tersebut berupa buku puisi berbentuk antologi, drama, prosa dan karya-karya ilmiah. Puisi dan dramanya banyak diterjemahkan ke dalam bahasa Inggris, Prancis, Cina dan Yugoslavia.

Proses pembacaan teks puisi menurut Michael Riffatere merupakan pembacaan melalui pikiran pembaca yang dilakukan pada tahap pembacaan kedua. Ada empat level yang harus dipahami dan dibedakan cara pembacaannya. Empat level tersebut adalah Heuristik yang dilakukan dalam pembacaan pertama, Hermeneutik pembacaan pada level kedua, ketiga matriks- model -varian dan terakhir hipogram.

7 Ntsond, P. An Analysis of selected poems from sefalana sa Menta by L.D. Raditladi with Reference to Riffaterre's and Lotman's Semiotics. The Potchefstroom Campus the NORTH-West University (2009)

8 Michael Riffatere, Semiotics Of Poetry (Bloomington; Indiana University Press, 1878). Hal. 81

${ }^{9}$ LM. Maulana. Semiotika Michael Riffatere (Analisis Pembaaan Heuristic-Hermeneutik atas Q.S. Ali Imran (3): 14). Jakarta: Qof. Vol. 3. No. 1. (2019), 68. 
a. Heuristik

Heuristik merupakan pembacaan melalui gramatikal dengan menyatukan tanda-tanda linguistic, yang menunjuk pada keadaan diluar puisi dan tidak mengaitkan pada tanda dan hubungannya. Sedangkan pembacaan pada level kedua yaitu Hermeneutik pembacaan yang lebih tinggi dengan cara menelusuri aspek-aspek di luar gramatikal dari puisi untuk mendapatkan maknanya secara tidak langsung. ${ }^{10}$ Dengan pembacaan Hermeneutik, kemudian akan muncul matriks yang menjadi tanda dalam sebuah puisi, biasanya berupa kata atau kalimat yang menjadi sebuah tanda atau pesan untuk puisi. Adanya pembacaan tahap matriks adalah cara agar puisi tersebut memberikan kesatuan puisi. ${ }^{11}$ Heuristik yang digunakan dalam pembacaan berdasarkan struktur bahasanya yang menghasilkan makna harfiah dan biasanya disebut dengan pembacaan tahap pertama, hermeneutic merupakan kata yang berasal dari hermeneuein yang berarti mengerti dan menerjemahkan. ${ }^{12}$

b. Hermeneutik

Pembacaan pada tahap ini menggunakan cara pembacaan ulang untuk mengetahui makna yang sebenarnya. Pembacaan secara struktural yang bergerak bolak-balik dari bagian ke keseluruhan ke bagagian dan seterusnya. ${ }^{13}$ Pada pembacaan hermeneutik akan menemukan bentuk ketidaklangsungan ekspresi yang disebabkan oleh 3 hal yaitu pergantian arti, penyimpangan arti dan penciptaan arti. Pertama Pergantian arti juga akan ditemukan dalam analisis semiotika ini, karena penggunaan bahasa kiasan tersebut menjadikan makna dan kalimat harfiah memiliki bentuk yang berbeda. Dan kedua penyimpangan arti, hal ini disebabkan oleh ambiguitas dalam puisi yang memiliki makna ganda dan menyebabkan multi tafsir, serta kontradiksi karena terjadi ironi atau paradox yang tujuannya untuk sindiran atau ejekan sehingga orang akan berfikir dan akan menarik perhatian. dan nonsense dalam puisi dikarenakan permainana bunyi. Ketiga penciptaan arti dikarenakan ketika ditafsirkan seara keseluruhan ternyata memiliki makna yang dalam disebabkan oleh rima, enjanjement dan tipografi. ${ }^{14}$

10 Raheleh, barador. Anita L. Semiotika Puisi Riffatere Dalam Membaca Ulang "Bright Star" karya John Keats dan Sepehri "ke Taman Rekan Wisatawan". Iran: Asian Journal of Multidiscciplinary Studies. Vol: 2, No. 9 (2014).

11 Ibid. Hal 119.

12 J. R Raco. 2010. Metode Penelitian Kualitatif. Jakarta: Grasindo.

13 Faruq. 1996. "aku” dalam semiotika Riffaterre. Yogyakarta: UGM.

14 M. Fawaid al Fikry dkk. 2019. Mantra Petapa Alas Purwo: Kajian Semiotika Riffaterre. Semiotika: Jurnal Ilmu Sastra dan Linguistik, Vol. 20. No. 2. (2019), 113. 
c. Menemukan matriks, Model dan Varian.

Teks dalam puisi merupakan perubahan dari matriks. ${ }^{15}$ Matriks menjadi motor atau generator sebuah teks dalam puisi, sedangkan model menentukan cara pemerolehan dan pengembangannya. Sehingga setelah menemukan matriks akan dikembangkan oleh model. Matriks merupakan kata kunci untuk menafsirkan puisi yang dikonkretisasikan. ${ }^{16}$ matriks diumpamakan seperti daging donat oleh Riffaterre. Terdapat dua bagian dalam donat yaitu daging donat dan bulatan kosong ditengah donat. Dua hal yang saling memiliki kepentingan. Puisi menjadi penopang yang menjadi pusat makna untuk ditemukan sedangkan matriks adalah ruang kosong tersebut. ${ }^{17}$ matriks yang merupakan kata kuni dalam sebuah puisi, model sebagai transformasi matriks, varian adalah masalah dan deksripsi dalam puisi sedangkan hipogram merupakan intertekstual dalam puisi yang digunakan untuk menghubungkan makna satu dengan makna lain. ${ }^{18}$ Dengan tahapan tersebut, penulis berharap akan ada pemaknaan yang lebih jelas. Model adalah kata atau kalimat yang mewakili bait dalam puisi. Sedangkan varian adalah bentuk penjabaran dari struktur yang sama dengan model. Sehingga dikatakan bahwa matriks, model dan varian adalah perkembangan dari puisi.

d. Hipogram

Hipogram merupakan keterkaitan karya sastra dengan karya yang lain. hal ini juga berkaitan dengan latar belakang sejarahnya, alam dan kehidupan yang dialami oleh penyair. Hipogram merupakan ruang kosong yang menjadi pusat makna suatu puisi yang harus ditemukan. ${ }^{19}$

Puisi fii ainika unwani karya Faruq Juwaidah :

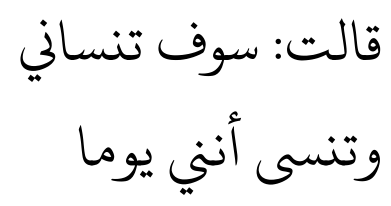

15 Yulia Nasrul Latifi, Puisi ana karya Nazik Al-Mala'ikah (Analisis Semiotik Riffaterre). Adabiyyat, Vo. 12, No. 1, (2013), 25-55.

16 Pradopo, 2008. Hal 299.

17 Galuh, Syafahati. Semiotika Riffaterre: kasih sayang pada puisi An Die Freude Karya Johan Christoph Friedrich Von Shiller. (Yogyakarta: Univ. Negeri Yogyakarta, 2016).

18 Rusmita Sipahutar. An Analysis of Semiotic Riffaterre in Walt Whitman Selected Poem. (Batam: Univ. Putera Batam, 2019).

${ }^{19}$ Michael Riffatere, Semiotics Of Poetry (Bloomington; Indiana University Press, 1878). 


$$
\begin{aligned}
& \text { وهبتك نبض وجداني } \\
& \text { وتعشق موجة أخرى وهيت نيض وجدا } \\
& \text { وتهجر دفء شطآني } \\
& \text { وتجلس مثلما آنا } \\
& \text { لتسمع بعض ألحاني } \\
& \text { ولا تعنيك أحزاني } \\
& \text { ويسقط آلمنى اسمي } \\
& \text { وسوف يتوه عنواني } \\
& \text { ترى.. ستقول يا عمري } \\
& \text { بأنك آنت تهواني! } \\
& * * \\
& \text { فقلت: هواك إيماني } \\
& \text { ومغفرتي.. وعصياني } \\
& \text { أتيتك والمنى عندي } \\
& \text { بقايا بين أحضاني } \\
& \text { ربيع مات طائره } \\
& \text { على أنقاض بستان } \\
& \text { رياح الحزن تعصرني } \\
& \text { وتسخر بين وجداني } \\
& \text { أحبك واحة هدأت } \\
& \text { عليها آل أحزاني } \\
& \text { أحبك نسمة تروي } \\
& \text { لصمت الناس.. ألحاني }
\end{aligned}
$$




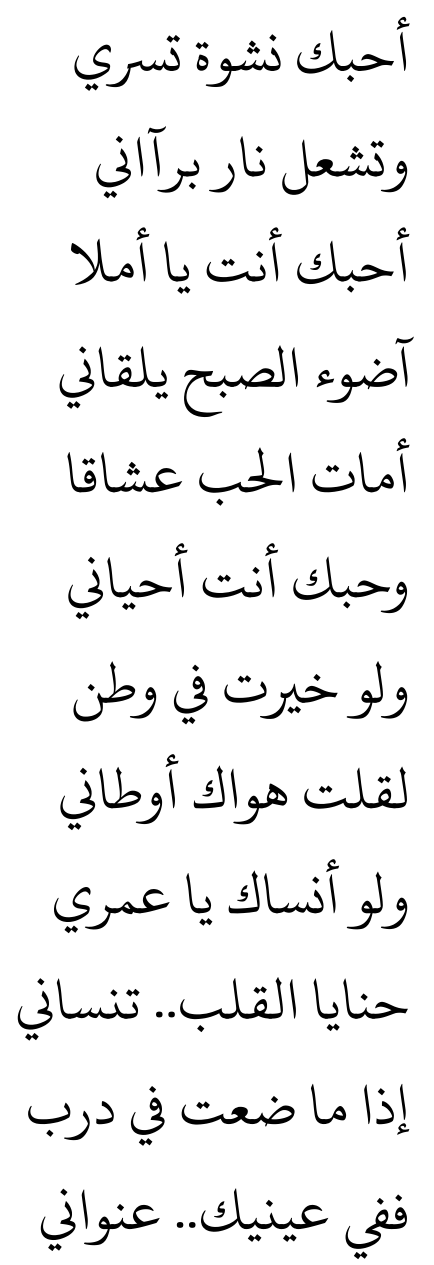

a. Analisis Pembacaan Heuristik

Pembacaan heuristik menempati kedudukan pertama dalam tingkat pertama yang fungsinya memperjelas arti dari segi kebahasaan. Pembacaan pada puisi ini sebagai berikut:

- قالت yang berarti “ dia perempuan berkata” dia disini merupakan orang yang penulis tuju untuk diceritakan dan dituangkan dalam puisi.

• قالت: سوف تنساني "Dia berkata : Kau akan melupakanku” kalimat tersebut dikatakan oleh perempuan yang penulis ceritakan dalam puisinya. Disini penulis menyatakan bahwa "kau" akan melupakan. 
• وتنسى Kang berarti lupa, يوما yang berarti kelak atau suatu saat. dalam kalimat tersebut mengartikan "kau" akan lupa pada suatu saat kepada aku.

- وهبتك نبض وجداني "Pernah mempersembahkan degup cintaku padamu”. Pada kalimat هبتك dempersembahkan dan هبتك degup cinta. Kalimat tersebut mengartikan perempuan tersebut memberi sebuah cintanya.

- ل وتعشق "Sekali lagi, kau akan mencintai debur ombak وتعشق موجة أخرى berarti mencintai, موجة berarti debur ombak. Akan tetapi, tidak disebutkan maksud dari kata mencintai debur ombak tersebut.

وتهجر .Meninggalkan kehangatan pantai - pantaiku" وتهجر دفء شطآني artinya meninggalkan, دفء artinya kehangatan, شطآني artinya pantai pantaiku. Kehangatan itu identik dengan cuaca. meninggalkan dan pantaipantai ku tidak memiliki makna yang di jelaskan.

• بجلس . Kau duduk seperti kita bersama” و وتجلس مثلما آنا duduk, مثلما yang berarti seperti, sedangkan آنا berarti saya atau aku.

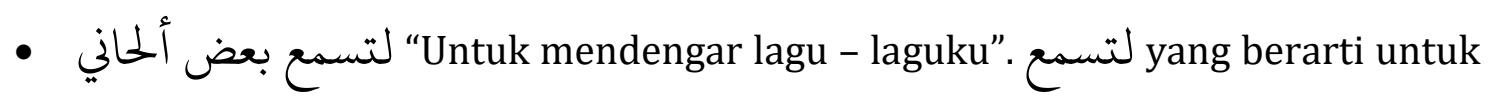
kamu mendengar, ألحاني yang berarti lagu-laguku. Dan بعض disini tidak dijelaskan sebagian atau bagian dari lagu-lagu itu.

• تعنيك ولاك .Namun kau tak peduli pada kesedihanku” تعنيك أحزاني yang berarti tak memperhatikan atau tak peduli. أحزاني berarti kesedihanku. 
• يسقط . يسط "sebagaimana harapan , hancurlah namaku" ويسقط آلمنى اسي jatuh, hancur, آلمنى berarti harapan, اسيى yang berarti namaku. Disini tidak dijelaskan kenapa namanya dan bukan yang lain yang dimaksud hancur.

• سوف "kelak aku kehilangan alamatku" وسوف يتوه عنواني yang berarti kelak, عنو اني yang berarti alamatku. Alamat pada kalimat ini tidak dijelaskan secara gambling maksud akan kehilangan alamat tersebut.

• ترى .dan ternyata, kau katakan, oh kekasih hidupku”. ترى. ستقول يا عمري yang berarti dan ternyata, ستقولyang berarti kau katakan, يا عمري yang berarti oh kekasih hidupku. Maksud dalam kalimat ini tidak diperjelas.

• بأنك آنت تهواني؟ "bahwa kau begitu mencintaiku?!”. تهواني yang berarti mencintaiku. Maksud tanda Tanya dan seru tidak dicantumkan maksud yang tersurat.

- ku katakan”. Seorang “aku” ingin mengatakan sesuatu. Apa hubungan aku dengan kau yang dieritakan dalam puisi?

• هواك إيمانك bencintaimu adalah imanku” "mencintaimu, هواكي berarti imanku. Penulis puisi tidak menjelaskan kenapa cinta isa dikaitkan dengan iman.

• ومغفرتي.. وعصياني "ampunan ku, durhakaku”. Penulis tidak menjelaskan kenapa terdapat ampunan dan bentuk durhaka itu menghubungkan arti yang seperti apa, karena terjadi ketidakkonsistenan dalam kalimat tersebut.

• أتيتك . dengan membawa harapan aku datang kepadamu” أتيتك والمنى عندي berarti datang, tidak dijelaskan maksud datangnya memiliki tempat yang 
dituju atau tidak. أتيتك berarti harapan, kalimat tersebut belum memberi gambaran harapan seperti apa yang ingin dibawa.

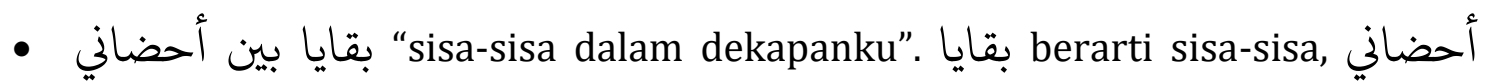
dekapanku. Dalam kalimat itu terdapat ambiguitas berupa apa yang didegap dan kenapa dekapan itu sisa-sisa? Apakah yang didegap itu berpa sesatu yang sdah berkurang atau memiliki maksud lain?

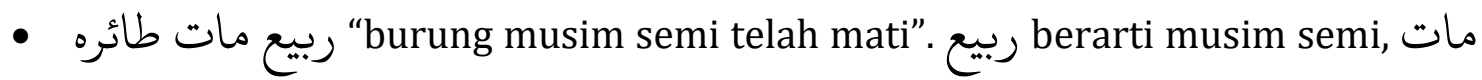
berarti mati dan طائره berarti burung. Tidak dijelaskan apakah burung yang mati di musim semi tersebut sedikit atau banyak?

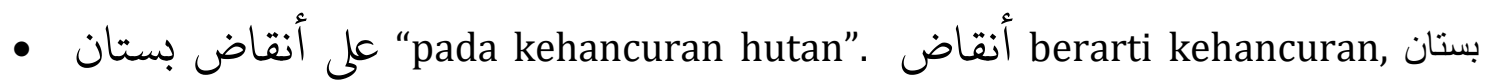
berarti hutan atau taman. Sebab apa kehancuran hutan tersebut tidak diketahui alasannya? Sehingga menimbulkan pertanyaan.

• رياح الحزن تعصرني "angin kesedihan menghantamku”. رياح berarti angin, الحزن berarti kesedihan, تعصرني berarti menghantamku. Sebab kesedihan tidak dijelaskan pada satu kalimat ini. dan hantaman tersebut berbentuk keras atau hantaman kecil tidak ada indikasi yang menjelaskan.

• وتسخر gerarti menundukkan, وجداني berarti cintaku. Menundukkan disini tidak dijelaskan bagaimana keadaan dia menunduk di hadapan cintaku. Sedangkan respond cintaku juga tidak dijelaskan dalam kalimat ini.

- أحبك berarti mencintaimu, هدأت berarti kesejukan. Keterkaitan mencintai menjadi kesejukan tidak menjadi hal lumrah untuk semua orang sehingga 
dipertanyakan kenapa mencintai "mu" bisa membuat kesejukan? Gambaran itu belum di perlihatkan dalam kalimat ini.

- yang mampu menenangkan kesedihanku”. Alasan kesedihan tersebut belum diperlihatkan secara gamblang dalam kalimat ini?

• "kumencintaimu sebagai semilir angin yang mengabarkan". berarti mengabarkan. Angina yang semilir menjadi perantara mengabarkan. Akan tetapi, apa yang menjadi kabar tidak dijelaskan apa?

• لصمت الناس.. ألحاني "untuk membungkam manusia, akan lagu-laguku”.

berarti membungkam, الناس berarti manusia, ألحاني berarti lagu-laguku. Membungkam manusia dengan lagu-lagu menjadi makna yang masih ambiguitas.

• "kumencintaimu sebagai ekstase yang menyergap”. أحبك " أحبك نشوة تسري نشوة berarti, kumencintaimu sebagai ekstase, تسري berarti menyergap. Ekstase atau kenikmatan mencintai "mu" di anggap sebagai hal yang menyergap.

- وتشعل نار برآآن "menyalakan gunung berapiku”. arti dari kalimat tersebut sangat ambigu, karena bagaimana bisa gunung berapi dapat dinyalakan oleh manusia?

- ل أحبك أنت يا أمب "kumencintaimu, wahai harapanku”. Ungkapan dari "ku” mencintai dan menganggap "mu" menjadi harapannya.

- "seperti cahaya subuh yang menerpaku”. Pada kalimat tersebut mengandung kata seperti cahaya subuh, hal ini menjadi pertanyaan 
kenapa penulis memilih subuh bukan pagi, atau malam untuk mengungkakan. يلقاني berarti menerpaku. Cahaya tersebut mengenai "ku".

- أمات berarti membunuh, عشاقا berarti para pecinta. Tidak diketahui alasan cinta dapat membunuh para pecinta dan kenapa bukan para pecinta yang membunuh cinta itu. Padahal pada kalimat subuh seperti sesuatu yang tenang.

- وحبك أنت أحياني "sedangkan mencintaimu, malah menghidupkanku”. Mencintai membuat dia menjadi merasa hidup.

• خ خيرت . "andai aku diberi pilihan tentang suatu negara" ولو خيرت في وطن berarti pilihan, في وطن berarti suatu Negara. Pada puisi ini tidak diketahui makna Negara itu diperumpamakan dengan apa? Dan kira-kira perandaian itu, siapa yang memberi pilihan?

- "kukatakan bahwa engkau adalah negeriku”. setelah dia berandai-andai diberi pilihan tentang seuatu Negara, dia memilih "engkau" menjadi negaranya.

- jلjika aku melupakanmu, oh kekasih hidupku”. dia memanggil kekasihnya.

• حنايا القلب.. تنساني "maka hatiku yang tulus, juga akan melupakanmu”. Pada kalimat-kalimat sebelumnya dia begitu mencintai. Tapi disini dia ingin melupakan. Hal ini dua keinginan yang bertolak belakang.

• إذا ما ضعت في درب “jika aku tersesat ditengah jalan”. Setelah dia mengatakan begitu mencintai, kemudian ingin melupakan dan tiba-tiba ia mengatakan tersesat. 
- di matamu alamat ku”. Ambigu bagi beberapa pembaca jika mata menjadi sebuah alamat. Kenapa bukan hati atau lainnya?

b. Pembacaan Hermeneutik

Pembacaan tahap kedua yang disebut dengan pembacaan retroaktif. Proses pembacaan Hermeneutik membutuhkan tahap yang bersungguh-sungguh untuk memberikan penafsiran melalui rangkaian Hermeneutik.

Bait pertama sampai tiga bentuk pernyataan yang mencari jawaban akan perasaan yang sedang diungkapkan. Dalam bait ke empat dan kelima menyamakan kata debur ombak dengan keteguhan dalam menyikapi sesuatu. Hal ini menggambarkan akan baik-baik saja tanpa dia.

Bait keenam dan ketujuh, وتجلس مثلما آنا menggunakan kata "saya” yang diartikan ke dalam bentuk kita. Bait ini untuk mengingat bentuk kebersamaan mereka sebelumnya yaitu mendengarkan lagu-lagunya. Sedangkan dalam bait ke delapan sampai sepuluh, tokoh dia (perempuan) merasa jika tokoh "aku" akan lupa dan tidak peduli dengan bentuk kesedihannya. Selain itu, dia juga mengatakan dalam bait Sembilan 'sebagaimana harapan, hancurlah namaku", Nama identik dengan identitas seseorang, dia menggambarkan identitasnya menjadi kekasih akan hilang atau terhapus dalam ingatan dan perasaan tokoh "aku". Dia memperumpamakan identitasnya hilang seperti harapannya. Dengan kehilangan harapan sekaligus identitas menandakan dia juga akan kehilangan alamatnya yang merupakan tanda atau tujuan perasaannya tersebut. Bait sebelas dan dua belas, terlihat tokoh "dia" begitu terkejut dengan pernyataan tokoh "ana" yang mengatakan begitu mencintainya. Akan tetapi penulis puisi dalam bait dua belas masih menggunakan tanda seru dan tanda tanya, hal ini menggambarkan tookoh "dia" heran, kaget sekaligus hanya seolah-olah ilusi dan imajinasi dari perasaan dan pikirannya yang memikirkan suatu hal dengan berlebihan karena ketakutan akan kehilangannya. Mulai dari bait ke tiga belas dan selanjuutnya merupakan bentuk ungkapan dari tokoh "aku" yang menjawab dan meyakinan tokoh "dia" dalam puisi ini.

Bait ke tiga belas dan empat belas "kukatakan, mencintaimu adalah imanku, ampunan ku, durhakaku". Penulis menggunakan kata imanku dalam mengungkapkan cintanya, iman berarti sebuah bentuk kepercayaan, keyakinan seseorang, sehingga dia menyamakan keyakinananya dalam mencintai merupakan seperti bentuk iman. 
Sedangkan kata ampunanku disamakan dengan sebuah rahmat ataupun anugrah. Dan durhakaku bermakna keluar dari ketentuan, menyeleweng. Jika dimaknai secara keseluruhan, maka tokoh "aku" akan tetap mencintai dia walapun hal itu akan menjadi sebuah larangan maupun dicegah.

Bait kelima belas sampai akhir adalah ungkapan cinta dari tokoh "aku" sekaligus untuk meyakinkan dia menggunakan kalimat sederhananya. Pada bait enam belas, "membawa sisa-sisa dekapanku" merupakan ungkapan cinta yang sederhana dan penuh harapan. Sedangkan pada bait tujuh belas dan dua puluh menggunakan perumpamaan burung pada musim semi yang telah mati pada kehancuran hutan. Hal ini, bentuk keyakinannya jika cinta dan harapan akan datang dan ketakutannya akan pergi dan kesedihannya, dan terdapat jawaban dari kesedihannya terjawab pada bait dua puluh yang hanya akan terobati dengan pertemuannya bersama kekasih hati.

Pada bait dua puluh satu sampai dua puluh dua merupakan ungkapan dan kesadarannya ketika ia mencintainya adalah bentuk kesejukan, ketenangan dan kebahagiaan. Dan pada bait ke duapuluh tiga sampai dua puluh lima adalah cara dia meyakinkan pasangannya.

Uraian pada bait dua puluh tiga dan dua puluh empat adalah bentuk keinginanya bahwa orang lain harus tau bahwa bentuk jawaban dari lagu-lagunya adalah dia dan bait selanjutnya mengungkapkan jika mencintainya adalah kebahagiaan dan kenikmatan baginya. Bait dua puluh enam sampai tiga puluh dua adalah ungkapan bahwa dengan mencintainya adalah penting, indah dan dapat membuatnya semakin bersemangat. Bukan hanya sampai situ saja bentuk kesungguhan dan perasaannya, yaitu jika diberi pilihan tentang Negara, ia tetap akan memilih dirinya. Akan tetapi jika tokoh "aku" melupakan dia, ia menegaskan bahwa itu adalah aa dia melupaan dirinya sendiri karena ia mengatakan di "matamu alamatku".

c. Matrik, model dan Varian

Puisi adalah perkembangan dari matriks, model kemudian menjadi varianvarian. Matriks merupakan makna yang terdapat pada sebuah puisi. Matrik sebagai kata kunci untuk menafsirkan puisi. Matriks dalam puisi fii ainika unwanii Faruq Juwaidah ini secara umum menggambarkan tentang kasih sayang, cinta, takut kehilangan serta harapan. Cinta dan takut kehilangan tercermin dari tokoh "dia (perempuan)" yang ditulis dari puisi tersebut menceritakan ketakutannya kehilangan 
kekasih hati, sehingga dia berfikir bahwa kekasihnya akan lupa dan menjauhinya. Selain itu, ia jga berfikir bahwa kekasihnya akan mendengarkan lagu-lagunya tanpa dia. sedangkan harapan, cinta dan kasih sayang digambarkan pada tokoh "aku" yang meyakinkan "dia (perempuan)” dengan jawabannya yang meyakinkan. Cara tokoh "saya" meyakinkan yaitu dengan mengatakan bahwa cintanya pada kekasihnya adalah bentuk yakin yang sudah bulat, sedangkan cara dia meyakinkan dengan perbuatan yaitu melalui kedatangannya membawa harapan, cinta dan semangatnya. Puisi romantic Faruq Juwaidah terkenal dengan kesederhanaan cintanya.

Selain matriks, terdapat model dan varian. Model merupakan bait atau kalimat yang mewakili dalam puisi tersebut. model dalam puisi ini adalah cinta. Betapa cinta dapat membuat kebahagiaan datang tapi juga dapat menghancurkan seseorang. Model dalam puisi ini secara umum adalah ketika kita mencintai orang yang tepat akan membuat kita lebih baik sedangkan mencintai orang yang salah, cintalah yang akan membunuh para pecinta.

Melalui tahapan metriks, model dan kemudian di lanjutkan pada varian dalam puisi fii ainika unwani. Terdapat varian puisi yang ditekankan yaitu pada bait pertama yang telah mencakup inti yaitu : dia berkata, kau akan melupakanku. Dan varian pada bait ke tiga belas yang menjawab ketakutan dan harapan pada bait pertama yaitu Si aku menjawab, "mencintaimu adalah imanku".

d. Hipogram

Hipogram merupakan cara pembacaan puisi agar semakin maksimal. Teks menjadi latar penciptaan sebuah karya sastra. Hipogram merupakan kelompok asosiasi konvensional yang disebut dengan sistem deskriptif atau tema yang kompleks. Sedangkan puisi menurut Riffaterre adalah respon terhadap puisi sebelumnya. ${ }^{20}$ Sehingga dapat di gambarkan bahwa tokoh "aku" dalam puisi ini sedang menceritakan "Dia (perempuan)" yang ditulis dalam puisi ini. Hal ini menandakan tokoh "dia” yang menjadi objek puisi yang ditulis oleh kekasihnya dalam puisi romantisme tersebut. Penulis seolah-olah menceritakan puisinya kepada pembaca. Dalam bait puisi satu sampai tiga, tokoh "dia" mengkhawatirkan serta takut jika kekasihnya lupa bahwa dia pernah cinta dan memberikan semua cintanya. Hipogram pada puisi ini dilatarbelakangi oleh pengungkapan perasaan yang

20 Ahmad Rais. TM. Pembacaan semiotik Michael Riffaterre dalam Diwan Al-Imam Al-Syafii tentang motivasi Belajar dan keutamaan 'Alim. *Makasar: Diwan, 2019). 
diceritakan, harapan dan bentuk saling mencintai. Cinta itu diungkapkan dengan cara menginggatkan kekasihnya bahwa dia pernah memberi semua cintanya, dan ketakutannya jika harus kehilangan. Akan tetapi penulis puisi itu juga memberi jawaban dengan memberi harapan dan keyakinan.

\section{SIMPULAN}

Puisi yang dianalisis menggunakan teori semiotic Riffaterre ini melihat pada bentuk ketidaklangsungan puisi serta kesatuan makna. Menggunakan beberapa tahap kerja teori yaitu level heuristik yang hanya melihat struktur puisi, hermeneutik mencari unsur-unsur pembentuk puisi untuk mendapatkan kesatuan makna dan menggunakan matriks, model dan varian, dan terakhir adalah hipogram. Pembacaan pertama dengan tahap heuristic secara gramatikal dan dilanjutkan dengan tahap hermeneutik pencarian makna dan Matriks dalam puisi fii ainika unwanii Faruq Juwaidah ini secara umum menggambarkan tentang kasih sayang, cinta, takut kehilangan serta harapan.Varian puisi yang ditekankan yaitu pada bait pertama yang telah mecakup inti yaitu : dia berkata, kau akan melupakanku. Dan varian pada bait ke tiga belas yang menjawab ketakutan dan harapan pada bait pertama yaitu "aku menjawab, mencintaimu adalah imanku". Model dalam puisi ini secara umum adalah ketika kita mencintai orang yang tepat akan membuat kita lebih baik sedangkan mencintai orang yang salah, cintalah yang akan membunuh para pecinta. Hipogram pada puisi ini dilatarbelakangi oleh pengungkapan perasaan yang diceritakan melalui harapan.

\section{DAFTAR PUSTAKA}

Al Fikry. M. Fawaid dkk. 2019. Mantra Petapa Alas Purwo: Kajian Semiotika Riffaterre. Vol. 20. No. 2.

Andayani. Kodrat Eko Strategi ampuh memahami makna puisi (teori semiotika Michael Riffaterre dan penerapannya). Jawa Barat: Eduvision.

Barador, Raheleh. Anita L. 2014. Semiotika puisi Riffatere dalam membaca ulang "Bright Star" karya John Keats dan Sepehri "ke taman Rekan Wisatawan". Iran: Asian Journal of Multidiscciplinary Studies. Vol: 2, issue 9. 
Faruq. 1996. " $a k u$ " dalam semiotika Riffaterre semiotika Riffaterre dalam "aku". Yogyakarta: UGM.

Hartono. 2014. Semiotika Riffaterre dalam Durrga Umayi karya Y. B Mangunwijaya. Yogyakarta: Universitas Negeri Yogyakarta.

Maulana. LM. 2019. Semiotika Michael Riffatere (Analisis Pembacaan HeuristicHermeneutik atas Q.S. Ali Imran (3) : 14). Jakarta: Qof. Vol. 3. No. 1.

Nasrul L, Yulia. 2013. Puisi ana karya Nazik Al-Mala'ikah (Analisis Semiotik Riffaterre). Yogyakarta: UIN Sunan Kalijaga. Vol. XII. NO 1. Hal. 27.

P. Agnes. Amelia S. 2020. Seni mengenal Puisi. Bogor: Guepedia.

P. Ntsanda. 2009. 2009. An Analysis of selected poems from sefalana sa Menta by L.D. Raditladi with Reference to Riffaterre's and Lotman's Semiotics. The Potchefstroom Campus the NORTH- West University.

Pradopo, Rahmat Djoko. 1987. Pengkajian puisi. Yogyakarta: Gadjah Mada University Press.

Raco, J. R. 2010. Metode Penelitian Kualitatif. Jakarta: Grasindo.

Riffatere, Michael. 1878. Semiotics of poetry (Bloomington; Indiana University Press.

Sipahutar, Rusmita. 2019. An Analysis of Semiotic Riffaterre in Walt Whitman Selected Poem. Batam: Univ. Putera Batam.

Syafahati, Galuh. 2016. Semiotika Riffaterre: kasih sayang pada puisi An Die Freude Karya Johan Christoph Friedrich Von Shiller. Yogyakarta: Univ. Negeri Yogyakarta.

TM, Ahmad Rais. 2019. Pembaaan semiotik Michael Riffaterre dalam Diwan Al-Imam Al-Syafii tentang motivasi Belajar dan keutamaan 'Alim. Makasar: Diwan. 